\title{
Measles, Rubella and Varicella IgG Seroprevalence in a Large Refugee Cohort in Germany in 2015: A Cross-Sectional Study
}

\author{
Alexandra Jablonka (D) Christine Happle $\cdot$ Martin Wetzke \\ Christian Dopfer · Sonja Merkesdal · Reinhold E. Schmidt · Georg M. N. Behrens • \\ Philipp Solbach
}

Received: July 19, 2017 / Published online: September 5, 2017

(c) The Author(s) 2017. This article is an open access publication

\section{ABSTRACT}

Introduction: The current extent of migration to the European continent is associated with exceptional humanitarian challenges. In 2015, Western Europe faced an enormous immigration of refugees with largely unknown protection status against communicable diseases. To adapt vaccination strategies, we aimed at assessing seroprevalences against three of the most relevant vaccine preventable diseases (VPD) in a large representative cohort.

Alexandra Jablonka and Christine Happle contributed equally to this work.

Enhanced content To view enhanced content for this article go to http://www.medengine.com/Redeem/ A2FBF0604986044A.

A. Jablonka ( $₫)$. S. Merkesdal · R. E. Schmidt . G. M. N. Behrens

Department of Clinical Immunology and Rheumatology, Hannover Medical School, Hannover, Germany

e-mail: jablonka.alexandra@mh-hannover.de

A. Jablonka · S. Merkesdal · R. E. Schmidt .

G. M. N. Behrens · P. Solbach

German Center for Infection Research (DZIF),

PARTNER Site Hannover-Braunschweig, Hannover,

Germany

C. Happle $\cdot$ M. Wetzke $\cdot$ C. Dopfer

Department of Pediatric Pneumology, Allergology, and Neonatology, Hannover Medical School,

Hannover, Germany
Methods: IgG seroprevalences for rubella, varicella $(n=554)$ and measles $(n=552)$ were analyzed in inhabitants of a Northern German refugee camp in the summer of 2015.

Results: Of the refugees, $77.9 \%$ were male (mean age 27.4 years for male and 26.8 years for female migrants). Most refugees came from the Eastern Mediterranean region (83.4\%), followed by immigrants from Eastern Europe (7.4\%), Africa (4.6\%), or other regions (4.5\%). The vast majority of migrants were protected against the three VPD: overall IgG seropositivity was $88.5 \%$ for measles, $77.9 \%$ for rubella and $95.9 \%$ for varicella. However, seroprevalences showed ageand origin-dependent differences. Varicella immunity, for example, was lowest in the youngest age group of both genders $(10.1 \%$ of male $/ 4.5 \%$ of female seronegative refugees

\footnotetext{
C. Happle

German Center for Lung Research, Biomedical

Research in End Stage and Obstructive Lung

Disease/BREATH, Hannover, Germany

P. Solbach

Department of Gastroenterology, Hepatology and

Endocrinology, Hannover Medical School,

Hannover, Germany
} 
$<18$ years vs. $100 \%$ seropositivity in men and women $>49$ years of age), and Sudanese migrants displayed particularly low rates of protection against varicella.

Conclusion: In accordance with previous studies, our analyses show an overall satisfactory seropositivity against measles, rubella, and varicella in refugees entering Europe during the current exodus. However, this rate is not sufficient for preventing transmission. For example, the rate of $12.9-17.9 \%$ female refugees at reproductive age unprotected against measles and the low protection levels against varicella in minors observed in our cohort emphasizes the need for stringent vaccination strategies in refugees coming to Europe during the current crisis.

Keywords: Asylum seeker; Infectious disease; Measles; Migration; Refugees; Rubella; Seroprevalence; Vaccination; Vaccine preventable disease; Varicella

\section{INTRODUCTION}

During the current refugee crisis, Western Europe is one of the leading destinations for migrants from countries such as Syria, Afghanistan, and Iraq. In the third quarter of 2016, for example, people from 146 countries were first-time asylum seekers in the EU [1]. Due to the breakdown of immunization programs in their countries of origin, young migrants are especially at an increased risk to suffer from life-threatening vaccine preventable diseases (VPD) such as polio and measles [2, 3]. Only a minority of refugees have access to regular health care and routine vaccination services [4]. This is a dilemma, as overcrowding, physical and psychological stress, malnutrition, and poor water and sanitation supply put migrants at particular risk for infection with VPD $[5,6]$. Refugee camps in the Middle East, Turkey, and EU countries are often overcrowded, and the implementation of uniform immunization guidelines for displaced populations is a major challenge in this situation [5, 7]. Data on the vaccination status of migrants entering Europe is scarce. Thus far, vaccination regimens in migrants have not been successfully harmonized.

A cornerstone for stringent development of vaccination guidelines for the migrating population is the knowledge on IgG seropositivity against VPD in representative refugee cohorts. In the current article, we present data of seroprevalences against measles, rubella and varicella (MRV) in a large, unselected cohort of migrants that entered a refugee camp in Northern Germany during the current crisis. This data may help to assess the general risk of transmission of communicable diseases in refugee camps and, more importantly, facilitate evidence-based guidance regarding migrant vaccination against measles, rubella, and varicella.

\section{METHODS}

\section{Study Population and Serum Collection}

A total of $n=554$ refugees were tested at admittance to a reception center in Celle, Northern Germany, in August/September 2015. Medical examination at admittance was mandatory by asylum law for all refugees above the age of 12 years and voluntary for children below that age. Prior to testing, informed consent was obtained from all patients, and from parents of underage refugees. No age group was excluded from the sample collection. As serological testing was performed in a cross-sectional, consecutive manner at admission, the sample cohort is representative of all refugees above the age of 12 years admitted to the reception center. No refugee reported prior vaccination against MRV in Germany, and refugees were tested for measles, rubella, and varicella IgG prior to immunization that was performed as routine care. Based on their serological status, all patients were offered consecutive immunization if necessary.

\section{Serological Analyses}

Serum levels of IgG against varicella and rubella were assessed in 554 refugees, and against 
measles in 552. IgG levels were analyzed by chemiluminescence Immunoassays according to the manufacturer's recommendations (LIAISON XL, Fa. DiaSorin, Saluggia, Italy) in a diagnostic laboratory certified for routine serological testing according to DIN EN ISO 15189:2014. Threshold values regarded as protective immune statues were as follows: $>100 \mathrm{IU} / \mathrm{l}$ for varicella (borderline 50-100 IU/l; limit of detection $10.0 \mathrm{IU} / \mathrm{l}),>13.4 \mathrm{AU} / \mathrm{ml}$ for measles (limit of detection $5.0 \mathrm{AU} / \mathrm{ml}$ ) and $>11 \mathrm{IE} / \mathrm{ml}$ (borderline 9-11 IE/ml; limit of detection $3.0 \mathrm{IE} / \mathrm{ml}$ ) for rubella.

\section{Data Analysis}

Besides serological data, refugee-specific information on age, gender, and country of origin were extracted from an electronic database that was fully anonymized by the Malteser Hilfsdienst before being transferred to the scientists for further processing. All information was collected in routine clinical care.

\section{Statistics}

Statistical analyses were processed using SPSS v.24.0 or Graphpad Prism v.5.02. Calculation of MRV seroprevalence was performed according to above mentioned cut-off criteria, and 95\% confidence intervals (95\% CI) for prevalences were estimated by bootstrapping (simple, 1000 computations). Associations between categorical variables (e.g., immunity vs. age-group, gender, region of origin) were assessed using the Chi squared test. For comparison of seroprevalences, Fisher's exact testing was performed, and $p$ values below 0.05 were considered significant.

\section{Compliance with Ethics Guidelines}

All procedures followed were in accordance with the ethical standards of the responsible committee on human experimentation and with the Helsinki Declaration of 1964, as revised in 2013. Informed consent was obtained from all subjects included in the study. All analyses were approved by local authorities
(Institutional Review Board of Hannover Medical School approval\# 2972-2015). All patient information was anonymized prior to analysis.

\section{RESULTS}

Figure 1 illustrates age and gender distribution of the cohort. In total, serological data from $n=554$ migrants between the age of 1 and 67 years were obtained. The median age of all asylum seekers that were included in this analysis was 25.5 years (25 years for men and 27 years for women) and $78.0 \%$ of subjects were male (Fig. 1a). In each age group, more sera from male than female subjects were obtained (Fig. 1b), $16.4 \%$ of the refugees were minors (aged $0-17$ years), $3.8 \%$ were older than 49 years, but the vast majority of refugees (79.8\%) were adults between the age of 18 and 49 years. Following WHO classifications of macro-geographical (continental) regions, $78.5 \%$ of the tested individuals originated from the Eastern Mediterranean Region, 9.6\% from the African Region, $7.4 \%$ from the European Region, and $1.1 \%$ came from the South East Asian Region. In $3.4 \%$ of refugees, no data on their country of origin were available. Due to the low number of individuals, the last two groups were classified as originating from "other" regions (Fig. 1c). The most frequently reported countries of origin were the Syrian Arab Republic (43.9\%; 243/554), Afghanistan (13.7\%; 76/554) and Iraq with 7.6\% (42/554). Table 1 summarizes the five most frequently reported countries of origin. In total, they came from 28 different countries.

Anti-varicella and anti-rubella test results were available from 554 refugees, and anti-measles IgG titers were obtained from 552 . Overall varicella seroprevalence was $91.2 \%$ (95\% CI 88.8-93.3\%). Borderline titers were displayed by $2.2 \%$ (95\% CI $1.1-3.4 \%)$, and $6.7 \%$ (95\% CI $4.7-9.1 \%)$ of samples showed results below the defined cut-off and were regarded as negative $(2.5 \%$ (95\% CI $1.4-4.0 \%)$ of samples below detection limit). Overall rubella seroprevalence within the cohort was $86.6 \%$ (95\% CI 83.9-89.3\%), while $1.8 \%$ of migrants (95\% CI $0.7-2.9 \%)$ had a borderline test result and 

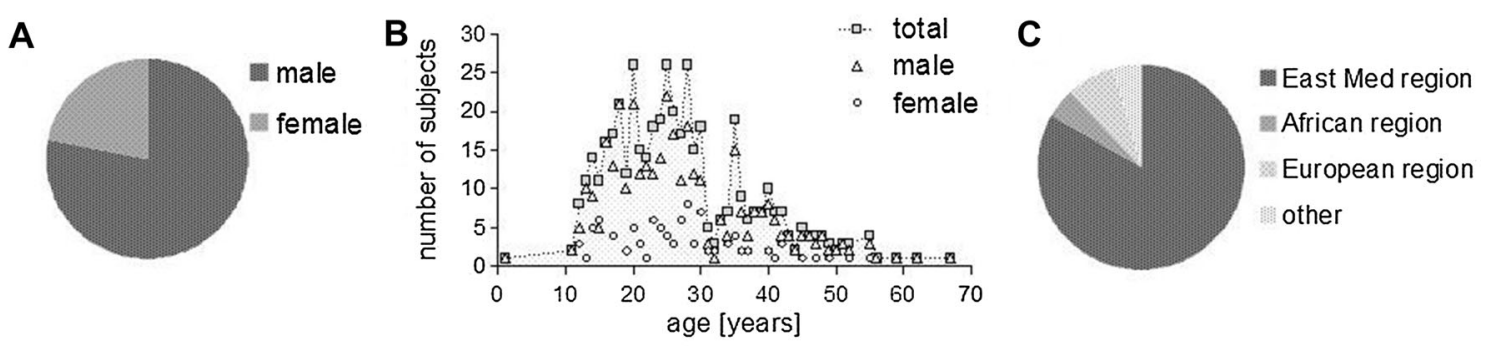

Fig. 1 a Gender distribution and $\mathbf{b}$ gender-dependent and total age distribution within the analyzed cohort. $\mathbf{c}$ Regions of origin of subjects within the analyzed cohort

Table 1 Top five countries of origin as reported by the tested migrants with disease specific seronegativity rates

\begin{tabular}{|c|c|c|c|c|}
\hline Region (top 5) & $n$ & Varicella $(95 \% \mathrm{CI})$ & Rubella (95\% CI) & Measels (95\% CI) \\
\hline Syria & 243 & $1.6(0.4-3.3)$ & $13.2(9.1-17.4)$ & $8.7(5.2-12.3)$ \\
\hline Afghanistan & 76 & $9.2(3.0-15.5)$ & $5.3(1.2-11.1)$ & $5.3(1.2-11.1)$ \\
\hline Iraq & 42 & $2.4(0-8.5)$ & $16.7(6.1-28.6)$ & $16.7(6.5-28.2)$ \\
\hline Pakistan & 39 & $17.9(6.8-31.2)^{* * *}$ & $2.6(0-8.6)^{*}$ & $2.6(0-8.6)$ \\
\hline Sudan & 25 & $40(21.1-60.0)^{* * *}$ & $0^{*}$ & $8(0-20.0)$ \\
\hline
\end{tabular}

$C I$ confidence interval

${ }^{*}$ and ${ }^{* * *} p<0.05$ in Fisher's exact testing against Syria

$11.6 \%$ (95\% CI $8.9-14.5 \%$ ) were below the defined cut-off, including $4.9 \% \quad(95 \%$ CI 3.2-6.5\%) below the limit of detection. Measles seroprevalence in all tested refugees was $89.9 \%$ (95\% CI $87.3-92.4 \%)$, while $10.1 \%$ (95\% CI $7.6-12.7 \%)$ of samples were below the defined cut-off, and 5.3\% (95\% CI 3.4-7.2\%) below the threshold of detection (Fig. 2a).

Female migrants showed an overall better protection levels against varicella $(95.5 \%$ protective immunity vs. $89.8 \%$ in males, significantly higher IgG level ( $t$ Test, $p<0.05)$. By contrast, males were better protected against rubella than females $(98.1 \%$ seropositivity in male vs. $77.9 \%$ in female refugees, $p$ value $<0.01)$. There were no significant differences in the antibody levels of measles between males and females (90.23\% vs. $88.52 \%$ seropositivity in males vs. females; Fig. 2a).

With regard to complete seropositivity against all three VPD, females had a slightly but insignificantly lower MRV protection rate ( $68.9 \%$ vs. $73 \%$ in males). In total, $27.9 \%$ of all tested refugees showed incomplete seropositivity against all three communicable diseases (Fig. 2b).

When we analyzed age-specific differences in seroprevalences within our cohort, we observed a rate $8.8 \%$ (95\% CI $3.3-14.3 \%)$ of children below the age of 18 years with seronegativity against varicella, and 7.7\% (95\% CI 2.2-13.2\%) were seronegative for anti-rubella IgG, and 5.5\% (95\% CI $1.1-11.0 \%)$ of minors were measles seronegative. By contrast, the oldest age group (migrants above 49 years of age) showed complete seropositivity against varicella, and 9.1\% (95\% CI $0-22.7 \%)$ of these refugees were unprotected against rubella and 4.8\% (95\% CI 0-14.3\%) against measles (Fig. 3a-c). Detailed information on age-dependent serological status is given in Table 2 .

When we analyzed the levels of complete protection against all three VPD in defined subgroups of our cohort, we observed no specific age or gender dependent differences. Overall, $76.9 \%$ of underage refugees and $68.4-75 \%$ of migrants in the adult age groups were completely MRV-protected (Fig. 3d). In 

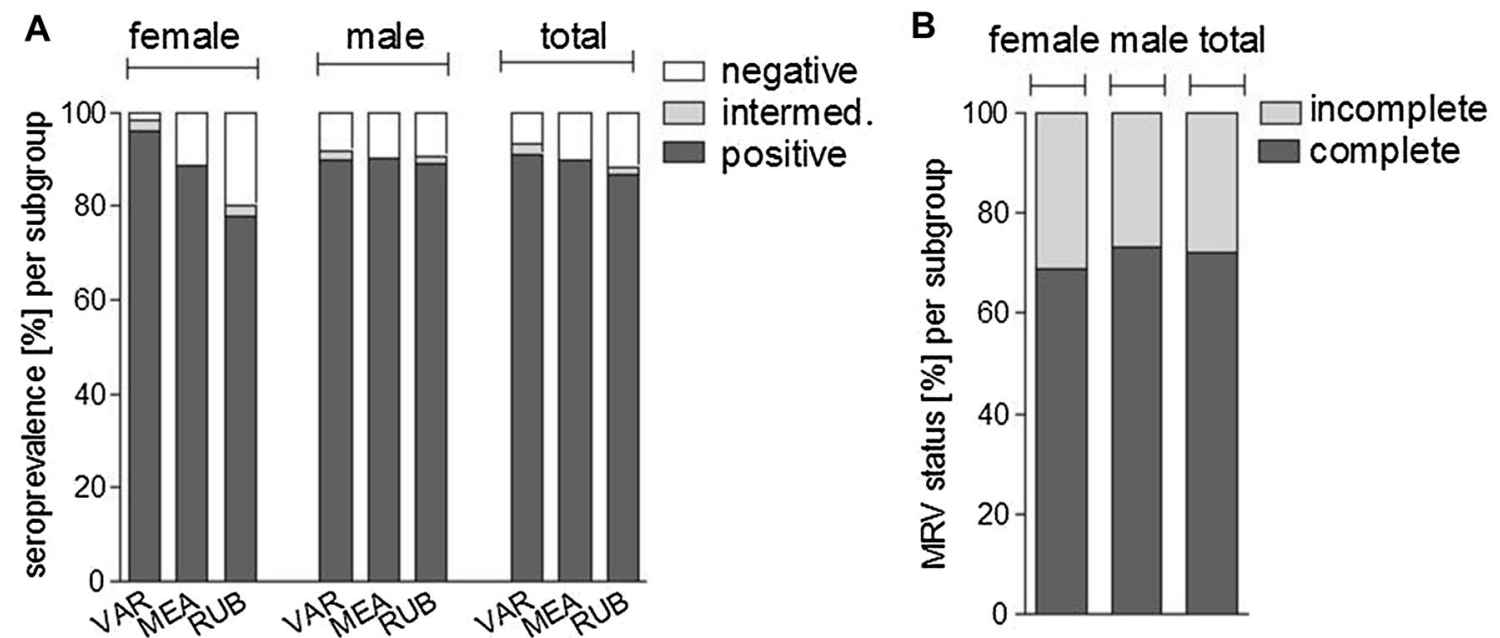

Fig. 2 a Seroprevalences against varicella $(V A R)$, measles $(M E A)$ and Rubella $(R U B)$ in female, male and all tested subjects. b Status of complete IgG seropositivity against all

female refugees, overall MRV protection was $77.3 \%$ in probands below the age of 18 years, followed by $71 \%$ in women between 18 and 24 years, $64.1 \%$ in women between 25 and 24 years, and $64.3 \%$ in women between 35 and 49 years. All tested women above the age of 49 years were seropositive for anti-MRV-IgG. In males, a similar proportion of underage children and adolescents were fully protected (76.8\%), whilst there were slightly higher MRV protection rates in men between 18 and 49 years $(75.6 \%$ in male refugees aged 18-24 years, $69.6 \%$ in those aged 25-34 years, $71.9 \%$ in those aged $35-49$ years), while $72.2 \%$ of male refugees above the age of 49 years were completely MRV seropositive (Fig. 3d).

Next, we analyzed seroprevalences with regard to the probands' regions of origin. Although no statistically significant differences between anti-varicella IgG seroprevalences based on the refugees' origins could be observed, protection levels were higher in subjects from the Eastern Mediterranean and European regions in comparison to those from the African region (seronegativity $4.9 \%$ and 6.5\% in European and Eastern Mediterranean subjects vs. $15.4 \%$ in African refugees; Table 3). Seronegativity for anti-rubella IgG was also not statistically significantly different between the tested subgroups, but was more common in

three tested VDP in tested women, men and all analyzed subjects. intermed intermediate, MRV measles/ rubella/varicella

refugees originating from Europe (22\%) than in those from Eastern Mediterranean regions $(10.4 \%)$ or Africa (15.4\%). Furthermore, no statistically significant differences between the seroprevalences of anti-measles IgG were observed, with again the highest rates of seronegativity in European subjects (22\%), followed by $19.2 \%$ of unprotected refugees from Africa and 8.7\% insufficient or negative titers in migrants from the Eastern Mediterranean region (Table 3 ).

When we analyzed the data according to a more defined specification of origin, we observed few significant differences between the IgG seroprevalences of varicella, rubella and measles in subjects from the top 5 countries of origin in our cohort. Syrian refugees displayed a significantly higher rate of anti-varicella IgG seropositivity in comparison to Pakistani and Sudanese migrants $(p<0.001)$. By contrast, seropositivity for anti-rubella IgG was significantly lower in Syrian compared to Pakistani and Sudanese refugees $(p<0.05)$ (Table 1$)$.

\section{DISCUSSION}

We have presented data on IgG seroprevalences against measles, rubella, and varicella in a large cohort of migrants entering a refugee camp in 
A

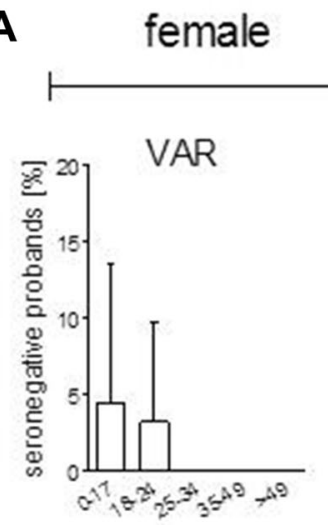

B

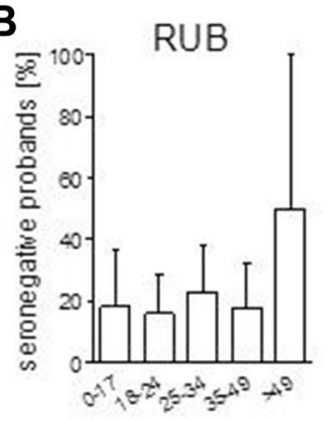

C

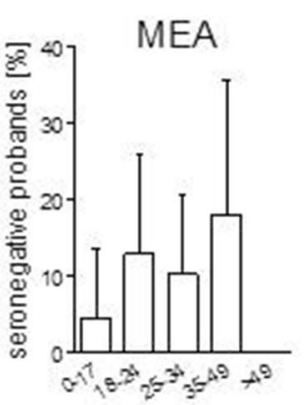

male
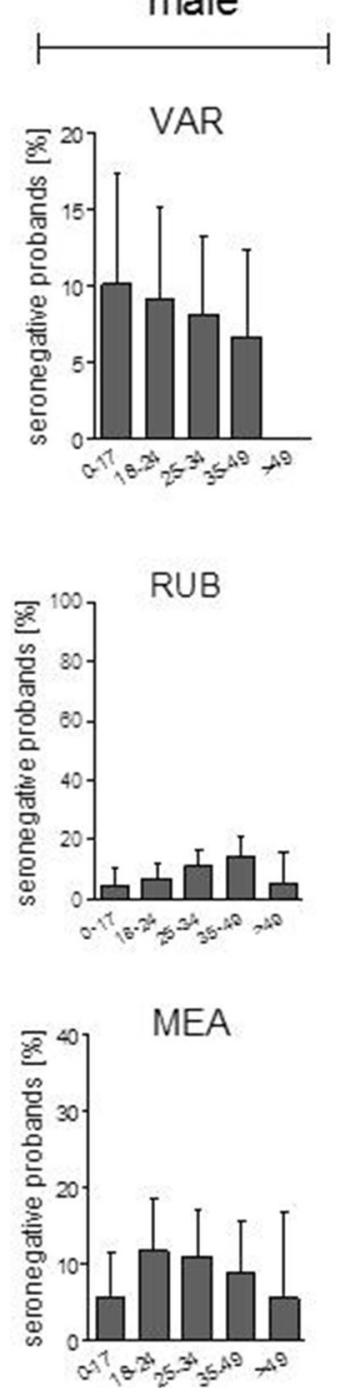

total

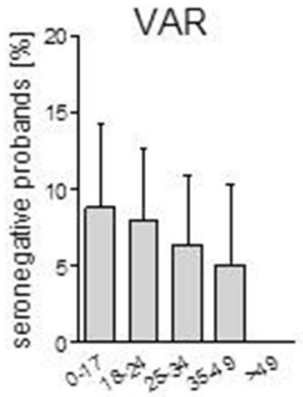

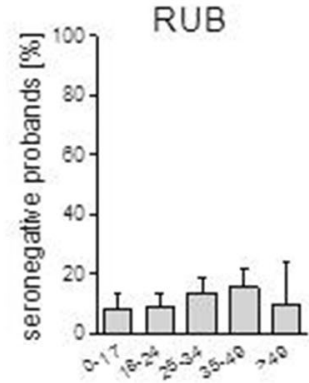

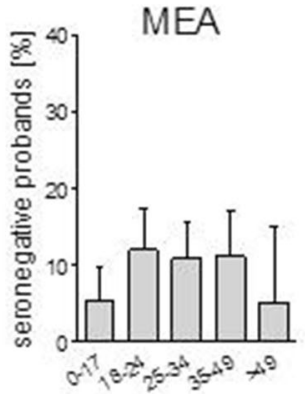

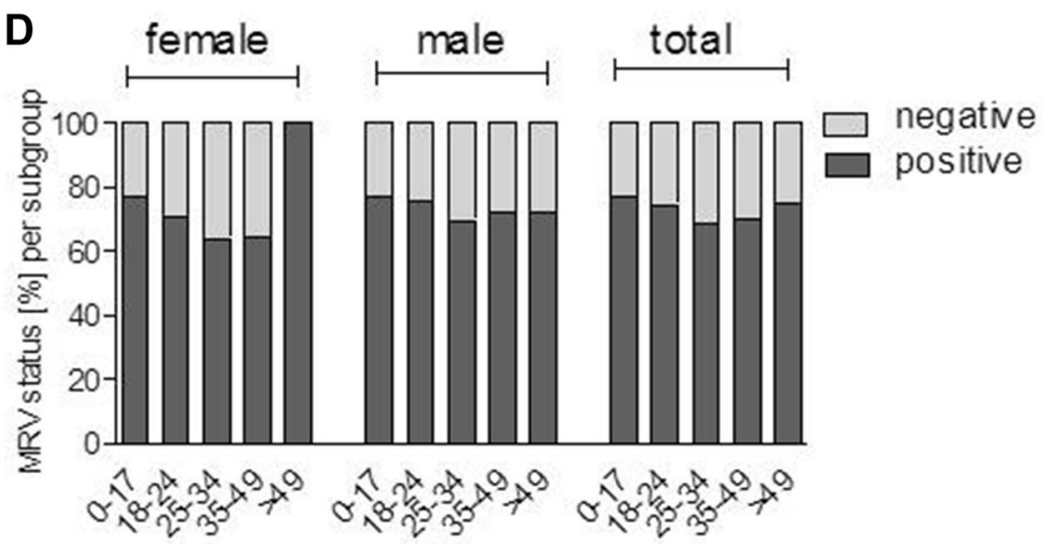


4Fig. 3 a Age-dependent rates of seronegativity of anti-varicella IgG in female, male, and all tested subjects (graphs display mean plus upper $95 \% \mathrm{CI}$ ). b Same presentation for rubella and c measles seronegativity. d Age-dependent status of complete IgG seropositivity against all three tested VDP in gender specific subcohorts and all tested probands. $M R V$ measles/rubella/varicella, $C I$ confidence interval

Northern Germany during the current crisis. The largest proportion of refugees in this cohort were young adults, and the vast majority of refugees $(78 \%)$ were males. As such, the described cohort is a representative demographic sample of the general population entering Western Europe during the current exodus that mainly consists of young, male adults [8-10]. Also, with regard to regions and countries of origin, our cohort reflects current demographics of the general refugee population currently "on the move". For example, $78.5 \%$ of subjects in our analysis came from the Mediterranean region and 9.6\% originated from Africa. This is in accordance with current statistics of the UNHCR, which show that the vast majority of all refugees presently seeking asylum in Western countries come from these regions [11].

Overall, we describe satisfactory seropositivity rates in the analyzed population, in which we observed protection rates of $89.9 \%$ against measles, $91.2 \%$ against varicella, and $86.6 \%$ against rubella. However, these rates are clearly lower than the WHO-demanded threshold of $95 \%$ for effective herd immunity against measles and rubella [12]. This finding is consistent with the slightly lower seropositivity rates reported by Toikkanen et al. of refugees entering in 2014/2015 [13] and higher MRV seropositivity rates in refugees entering Germany in August 2016, previously reported by our group [10]. This difference is most likely due demographic and geographical changes in the arriving refugee population.

We also show that vaccination rates are different depending on the refugees' regions of origin. For example, we observed particularly low seropostivity for varicella in Sudanese compared to Syrian refugees. Overall, $15.4 \%$ of tested African refugees in our cohort were seronegative for varicella IgG, compared to only
Table 2 Age-dependent seronegativity rates within the analyzed cohort

\begin{tabular}{|c|c|c|c|c|}
\hline $\begin{array}{l}\text { Age } \\
\text { group }\end{array}$ & $n$ & $\begin{array}{l}\text { Varicella } \\
(95 \% \mathrm{CI})\end{array}$ & $\begin{array}{l}\text { Rubella } \\
(95 \% \mathrm{CI})\end{array}$ & $\begin{array}{l}\text { Measels } \\
(95 \% \mathrm{CI})\end{array}$ \\
\hline $0-17$ & 91 & $\begin{array}{l}8.8 \\
\quad(3.3-14.3)\end{array}$ & $\begin{array}{l}7.7 \\
\quad(2.2-13.2)\end{array}$ & $\begin{array}{l}5.5 \\
\quad(1.1-9.9)\end{array}$ \\
\hline Male & 69 & $\begin{array}{l}10.1 \\
\quad(4.3-17.4)\end{array}$ & $4.3(0-10.1)$ & $\begin{array}{l}5.8 \\
\quad(1.4-11.6)\end{array}$ \\
\hline Female & 22 & $4.5(0-13.6)$ & $\begin{array}{l}18.2 \\
\quad(4.5-36.4)\end{array}$ & $4.5(0-13.6)$ \\
\hline $18-24$ & 150 & $\begin{array}{l}8.0 \\
\quad(3.3-12.7)\end{array}$ & $\begin{array}{l}8.7 \\
\quad(4.0-13.3)\end{array}$ & $\begin{array}{l}12.0 \\
\quad(7.3-17.3)\end{array}$ \\
\hline Male & 119 & $\begin{array}{l}9.2 \\
\quad(4.2-15.1)\end{array}$ & $\begin{array}{l}6.7 \\
\quad(2.5-11.8)\end{array}$ & $\begin{array}{l}11.8 \\
\quad(5.9-18.5)\end{array}$ \\
\hline Female & 31 & $3.2(0-9.7)$ & $\begin{array}{l}16.1 \\
\quad(3.2-29.0)\end{array}$ & $\begin{array}{l}12.9 \\
\quad(3.2-25.8)\end{array}$ \\
\hline $25-34$ & 175 & $\begin{array}{l}6.3 \\
\quad(2.9-10.9)\end{array}$ & $\begin{array}{l}13.7 \\
\quad(9.1-18.8)\end{array}$ & $\begin{array}{l}10.9 \\
\quad(6.3-15.5)\end{array}$ \\
\hline Male & 136 & $\begin{array}{l}8.1 \\
\quad(3.7-13.2)\end{array}$ & $\begin{array}{l}11.0 \\
\quad(5.9-16.9)\end{array}$ & $\begin{array}{l}11.1 \\
\quad(5.9-17.0)\end{array}$ \\
\hline Female & 39 & 0 & $\begin{array}{l}23.1 \\
\quad(12.8-38.5)\end{array}$ & $\begin{array}{l}10.3 \\
\quad(2.6-20.5)\end{array}$ \\
\hline $35-49$ & 117 & $\begin{array}{l}5.1 \\
\quad(1.7-10.3)\end{array}$ & $\begin{array}{l}15.4 \\
\quad(9.4-21.4)\end{array}$ & $\begin{array}{l}11.1 \\
\quad(6.0-17.1)\end{array}$ \\
\hline Male & 89 & $\begin{array}{l}6.7 \\
\quad(2.2-12.4)\end{array}$ & $\begin{array}{l}14.6 \\
\quad(7.9-21.3)\end{array}$ & $\begin{array}{l}9.0 \\
\quad(3.4-15.7)\end{array}$ \\
\hline Female & 28 & 0 & $\begin{array}{l}17.9 \\
\quad(7.1-32.1)\end{array}$ & $\begin{array}{l}17.9 \\
(7.1-35.6)\end{array}$ \\
\hline$>49$ & 21 & 0 & $9.5(0-23.8)$ & $5.0(0-15.0)$ \\
\hline Male & 19 & 0 & $5.3(0-15.8)$ & $5.6(0-16.7)$ \\
\hline Female & 2 & 0 & $50(0-100)$ & 0 \\
\hline
\end{tabular}

$C I$ confidence interval

6.5\% from the Eastern Mediterranean and 4.9\% from the European region. This is accordance with previously reported poor varicella immunization rates in African refugees, and fits with the seroprevalences of Toikkanen et al. and a recent report of a varicella outbreak amongst 
Table 3 Seronegativity rates of refugees with regard to their regions of origin

\begin{tabular}{lrclc}
\hline Region & \multicolumn{1}{c}{$\boldsymbol{n}$} & Varicella (95\% CI) & Rubella (95\% CI) & Measels (95\% CI) \\
\hline Eastern Mediterranean Region & 462 & $6.5(4.3-8.9)$ & $10.4(7.8-13.2)$ & $8.7(6.3-11.3)$ \\
African Region & 26 & $15.4(3.8-30.8)$ & $15.4(3.8-30.8)$ & $19.2(3.9-34.6)$ \\
European Region & 41 & $4.9(0-12.2)$ & $22.0(9.8-34.1)$ & $22.0(9.8-36.6)$ \\
Other & 25 & $4.0(0-16.0)$ & $12.0(0-27.9)$ & $8.0(0-20.0)$ \\
\hline
\end{tabular}

CI confidence interval

Sudanese migrants in a French refugee camp in 2015 [13, 14].

Vaccination is most efficient and important at a young age $[15,16]$, and, especially, the vaccination of young girls against measles, rubella, and varicella may not only protect the girl and women herself from life-threatening infection courses but, importantly, also prevent intrauterine virus transmission with potentially disastrous outcome for the fetus and baby $[17,18]$. Of note, the rate of female subjects unprotected against rubella in our cohort was higher in all age groups compared to their male counterparts-around $20 \%$ in all women at fertile age had no anti-rubella IgG.

In many cases, health care at admission to refugee housing is the only access young migrants have to vaccination programs, and, even if they are not granted long-term asylum in their desired country of destination, updated and stringent immunization will-in the long run-help them to live healthy and resistant lives.

Mipatrini et al. recently highlighted several challenges with regard to the implementation of effective refugee vaccination in Europe [19]. The authors mention that stringent vaccination of migrants poses a particular problem because most vaccines require repetitive immunization at regular intervals, but refugees are oftentimes constantly "on the move" and may refuse registration with medical authorities for fear of legal consequences. Furthermore, they are in many cases underinformed regarding their personal immunization status and pending shots. Also, many of the hosting countries are currently undergo economic struggles that prohibit effective coordination between health care authorities of neighboring countries.
To tackle these issues, information campaigns and significant improvement of communication structures among public health authorities of European countries is necessary. Current recommendations for refugees' first contact with the national health care system in Germany, for example, advise the performing of a basic but thorough clinical screening. By applying the "same high standard medical care as to the general population", treatment for acute medical problems as well as a closure of possible vaccination gaps should be pursued. All data at initial visit should be collected in a database that, in the long run, should provide the structure for effective communication between European health care providers concerned with migrant care. After transfer of the migrants into their destination community, outpatient and inpatient care providers should collaborate to update personal vaccination schedules as recommended by the national vaccination committee [15]. The authors fully support these recommendations.

One major limitation of our work is that seroprevalence cannot accurately reflect protection rates, as IgG levels wane after immunization, even though the individual might still be protected. However, the analysis of serological samples is currently the only feasible method of assessing protection in the absence of comprehensive vaccine documentation.

Another limitation of the study is that the number of older refugees is small in this cohort, representing the general refugee population. Furthermore, although young children were not the focus of our study, our cohort is only fully representative for inhabitants of the refugee camp who are older than 12 years-we show that, especially, the young subcohorts in our 
population display high rates of seronegativity against varicella. These results emphasize how important are stringent vaccination programs for children and young adolescents in migrating families. We have previously observed this problem in a similar cohort [10]. Due to the rather recent breakdown of previously functioning health care systems, such as, for example, in Syria, young refugees may especially have suffered from insufficient vaccination programs [2]. Further factors increasing the refugees' susceptibility to VPD infection, such as physical and psychological stress, malnourishment, overcrowding and poor hygiene during migration, may potentiate this problem $[4,15,19]$. Because refugee children, adolescents and young adults represent the majority of persons currently pursuing immigration into Western Europe, refugee health care providers need to be particularly aware of their medical needs $[2,7,11,15]$.

\section{CONCLUSION}

Taken together, our data show that seropositivity rates in refugees may depend on a refugee's origin, age, and gender, and that the overall seropositivity rate against VPD in the migrating population, which is particularly susceptible to communicable diseases, is well below WHO-demanded thresholds for effective herd protection. As such, our current analysis emphasizes the need for stringent implementations of vaccination guidelines during the current exodus, which poses extreme challenges to hosting health care systems $[11,17,20]$.

To preserve the refugees' as well as host community's health, protection from VPD is key, and we hope our current dataset will help to implement and update present guidelines in refugee medicine in Europe.

\section{ACKNOWLEDGEMENTS}

Alexandra Jablonka was funded by the Young Academy Clinician Scientist program of Hannover Medical School, Germany. Christine Happle received funding from the Young
Academy Clinician/Scientist foundation and HiLF funding of Hannover Medical School, Germany. The German Center for Infection Research provided infrastructural support. Articles processing charges were funded with the support of Hannover Medical School, Germany. All named authors meet the International Committee of Medical Journal Editors (ICMJE) criteria for authorship for this manuscript, take responsibility for the integrity of the work as a whole, and have given final approval for the version to be published.

Authorship contributions. Research design: Alexandra Jablonka, Georg M.N. Behrens, Reinhold E. Schmidt. Sample collection and analyses: Routine clinical care. Data analysis: Alexandra Jablonka, Christine Happle, Philipp Solbach, Martin Wetzke, Christian Dopfer, Sonja Merkesdal. Writing and contributing to writing of the manuscript: all authors. The authors would like to thank all doctors and medical personnel involved in medical care of the refugees for their exceptional work. Furthermore, the authors thank Malteser Hilfsdienst of Lower Saxony for their kind help with anonymized data provision.

Disclosures. Alexandra Jablonka, Christine Happle, Martin Wetzke, Christian Dopfer, Sonja Merkesdal, Reinhold E. Schmidt, Georg M.N. Behrens and Philipp Solbach have nothing to disclose.

Compliance with Ethics Guidelines. All procedures followed were in accordance with the ethical standards of the responsible committee on human experimentation and with the Helsinki Declaration of 1964, as revised in 2013. Informed consent was obtained from all subjects included in the study. All analyses were approved by local authorities (Institutional Review Board of Hannover Medical School approval\# 2972-2015). All patient information was anonymized prior to analysis.

Data Availability. The datasets during and/ or analyzed during the current study are available from the corresponding author on reasonable request. 
Open Access. This article is distributed under the terms of the Creative Commons Attribution-NonCommercial 4.0 International License (http://creativecommons.org/licenses/ by-nc/4.0/), which permits any noncommercial use, distribution, and reproduction in any medium, provided you give appropriate credit to the original author(s) and the source, provide a link to the Creative Commons license, and indicate if changes were made.

\section{REFERENCES}

1. Eurostat. Migration and migrant population statistics 2016. Available from: http://ec.europa.eu/ eurostat/statistics-explained/index.php/Asylum _ quarterly_report.

2. Cousins S. Syrian crisis: health experts say more can be done. Lancet. 2015;385(9972):931-4.

3. Eichner M, Brockmann SO. Polio emergence in Syria and Israel endangers Europe. Lancet. 2013;382(9907):1777.

4. Lam E, McCarthy A, Brennan M. Vaccine-preventable diseases in humanitarian emergencies among refugee and internally-displaced populations. Human Vaccines Immunother. 2015;11(11):2627-36.

5. Z. J. Population movement is a challenge for refugees and migrants as well as for the receiving population. Available from: http://www.euro.who.int/ en/health-topics/health-determinants/migrationand-health/news/news/2015/09/population-movement-is-a-challenge-for-refugees-and-migrants-aswell-as-for-the-receiving-population.

6. Kouadio IK, Koffi AK, Attoh-Toure H, Kamigaki T, Oshitani H. Outbreak of measles and rubella in refugee transit camps. Epidemiol Infect. 2009;137(11):1593-601.

7. Nicolai T, Fuchs O, von Mutius E. Caring for the wave of refugees in Munich. $\mathrm{N}$ Engl J Med. 2015;373(17):1593-5.

8. European Commission. Eurostat Asylum Statistics 2015. http://ec.europa.eu/eurostat/statisticsexplained/index.php/Asylum_statistics\#Asylum_ applicants. Eurostat. 2015. Accessed: 19.07.2017.

9. Buber-Ennser I, Kohlenberger J, Rengs B, Al Zalak Z, Goujon A, Striessnig E, et al. Human capital, values, and attitudes of persons seeking refuge in Austria in 2015. PLoS ONE. 2016;11(9):e0163481.

10. Jablonka A, Happle C, Grote U, Schleenvoigt BT, Hampel A, Dopfer C, et al. Measles, mumps, rubella, and varicella seroprevalence in refugees in Germany in 2015. Infection. 2016;44(6):781-7.

11. UNHCR. Figures at a glance 2017. http://www. unhcr.org/figures-at-a-glance.html. 2017. Accessed: 19.07.2017.

12. WHO. Renewed commitment to elimination of measles and rubella and prevention of congenital rubella syndrome by 2015 and Sustained support for polio-free status in the WHO European Region. Regional Committee for Europe Sixtieth session Moscow. 2010;13-16 September 2010.

13. Toikkanen SE, Baillot A, Dreesman J, Mertens E. Seroprevalence of Antibodies against Measles, Rubella and Varicella among Asylum Seekers Arriving in Lower Saxony, Germany, November 2014-October 2015. Int J Environ Res Public Health. 2016;13(7).

14. Lesens O, Baud O, Henquell C, Lhermet Nurse A, Beytout J. Varicella outbreak in Sudanese refugees from Calais. J Travel Med. 2016;23(5).

15. Pfeil J, Kobbe R, Trapp S, Kitz C, Hufnagel M. Recommendations for the diagnosis and prevention of infectious diseases in pediatric and adolescent refugees in Germany: Statement of the German Society of Pediatric Infectious Diseases, the Society of Tropical Pediatrics and International Child Health, and the Professional Association of Pediatricians. Internist. 2016;57(5):416-33.

16. Datta SS, O'Connor PM, Jankovic D, Muscat M, Ben Mamou MC, Singh S, et al. Progress and challenges in measles and rubella elimination in the WHO European Region. Vaccine. 2017;. doi:10.1016/j. vaccine.2017.06.042.

17. Gumpel SM, Hayes K, Dudgeon JA. Congenital perceptive deafness: role of intrauterine rubella. $\mathrm{Br}$ Med J. 1971;2(5757):300-4.

18. Hughes-Davies TH. Prevention of intrauterine rubella. Lancet. 1973;1(7809):943.

19. Castelli F, Sulis G. Migration and infectious diseases. Clin Microbiol Infect. 2017;23(5):283-9.

20. Jakab Z. Population movement is a challenge for refugees and migrants as well as for the receiving population. http://www.euro.who.int/en/healthtopics/health-determinants/migration-and-health/ news/news/2015/09/population-movement-is-achallenge-for-refugees-and-migrants-as-well-as-forthe-receiving-population. 2015. Accessed 19 Jun 2017. 